Original

\title{
Investigation of Spectrophotometrically Determined Substances in Yucca Extract by GC/MS, TLC and On-column Injection GC
}

(Received December 25, 2003)

\author{
Yoko Uematsu*, ${ }^{\dagger}$, Keiko Hirata*, Kumi Suzuki*, \\ Kenji IIDA* and Kunihiro Kamata* \\ (*Tokyo Metropolitan Institute of Public Health: 3-24-1, Hyakunin-cho, Shinjuku-ku, \\ Tokyo $169-0073$, Japan; ${ }^{\dagger}$ Corresponding author)
}

\begin{abstract}
Spectrophotometrically determined substances in Yucca extract, listed as "Yucca foam extract" in the "List of Existing Food Additives in Japan", were investigated by GC/MS, TLC and GC. A TLC method using an anisaldehyde color developing reagent similar to that employed in spectrophotometry was established for selective detection of sapogenins in Yucca extract. Several steroidal sapogenins were found by GC/MS in the fractions corresponding to spots on the TLC plate, and these were assumed to have contributed to the color development in spectrophotometry. Sarsasapogenin and smilagenin were the dominant sapogenins. An on-column injection GC method to determine these sapogenins in Yucca extract was also developed. The sum of these two sapogenins in Yucca extract was $0.9 \%$. The total amount of sapogenin estimated by GC was approximately $2 \%$, which was similar to that measured by spectrophotometry.
\end{abstract}

Key words: Yucca extract; Yucca foam extract; GC; GC/MS; TLC; sarsasapogenin; natural food additive; existing food additive; shelf-life extender

\section{Introduction}

Yucca extract (extract of whole plant of Yucca arborescens TREL. or Yucca schidigera ROEZL ex Orlgies) is listed as "Yucca foam extract" in the "Lists of Existing Food Additives in Japan", and its major use is as an emulsifier and processing agent ${ }^{1)}$. Because steroidal saponins in Yucca were reported to exhibit antiyeast or antifungal activities ${ }^{2}$, Yucca extract has been added to food particularly as a "shelf-life extender" (processing agent) in the Japanese market. Determination the saponins is important for the quality control of products, because products of poor quality can easily lead to deterioration of food, when used as shelf-life extenders. However, the official method to ensure quality for food additive use ("food additive specification") has yet to be established.

Previously, we developed a spectrophotometric method to determine the total amount of saponins in Yucca extract ${ }^{3)}$. The saponins in Yucca extract obtained by separation with HP- $20^{\circledR}$ were hydrolyzed, and the sapogenins generated were mixed with an anisaldehyde color developing reagent, heating developed a yellowish-green color with the maximum absorbance wavelength at around $430 \mathrm{~nm}$, and the absorbance was measured with a spectrophotometer. One of the drawbacks of spectrophotometry is that the compounds contributing to the absorbance are not known. Hence, identification of substances contributing to the color development would make the spectrophotometric method more reliable. The purpose of this work was to identify and quantitate the spectrophotometrically determined substances in Yucca extract by means of TLC and GC methods. Substances which contributed to the color development in spectrophotometry were separated and selectively detected on TLC with an anisaldehyde color developing reagent similar to that used in spectrophotometry. Fractions that corresponded to the detected spots were analyzed by GC/MS, and identified compounds were determined by GC.

\section{Materials and Methods}

\section{Samples}

Yucca extract was donated by Maruzen Pharmaceuticals Co., Ltd. (Hiroshima Japan).

\section{Standard substances}

Sarsasapogenin $\{(25 S)-5 \beta$-spirostan- $3 \beta$-ol $\}$ and smilagenin $\{(25 R)$ - $5 \beta$-spirostan-3 $\beta$-ol $\}$, (minimum, 98\%) were from Sigma-Aldrich Japan (Tokyo, Japan).

\section{Reagents}

Diaion HP-20 $0^{\circledR}$ was obtained from Mitsubishi Chemicals Co., Ltd. (Tokyo, Japan), $p$-anisaldehyde was from Wako Pure Chemical, Industries Ltd. (Osaka, Japan), and the solid-phase extraction column Bond Elut ${ }^{\mathbb{B}}$ (SI, $500 \mathrm{mg}$ ) was from Varian Analytical Instruments (California, USA). 


\section{Instruments}

Gas chromatography was performed on a GC-6890 (FID, Agilent Technologies, Palo Alto, USA). GC/MS was conducted with a mass spectrophotometer Automass 50 (EI, JEOL Ltd., Tokyo, Japan), and a gas chromatograph (HP 5890 series II, Agilent Technologies), equipped with an on-column injector (OCI-5, SGE International Pty., Ltd., Ringwood, Australia).

\section{TLC analysis}

Samples were prepared as described previously ${ }^{3)}$, except that the sapogenin generated was dissolved in 2 $\mathrm{mL}$ of ethyl acetate instead of $20 \mathrm{~mL}$. TLC was performed on silica gel 60 (High Performance Thin Layer Chromatography, HPTLC, $10 \times 10 \mathrm{~cm}$, layer thickness $0.2 \mathrm{~mm}$, without fluorescent indicator, Merck KGaA, Darmstadt, Germany). A $1 \mu \mathrm{L}$ volume of sample solution was applied, and developed with a hexane-ethyl acetate $(2: 1)$ mixture.

Coloring reagent was prepared as follows: $0.5 \mathrm{~mL}$ of $p$-anisaldehyde was dissolved in $9 \mathrm{~mL}$ of ethanol, to which $0.5 \mathrm{~mL}$ of sulfuric acid and $0.1 \mathrm{~mL}$ of acetic acid were added (anisaldehyde reagent). After drying, the plate was sprayed with the coloring reagent, and heated at $110^{\circ} \mathrm{C}$ for $10 \mathrm{~min}$.

\section{Investigation of color-developing substances}

(1) Preparation of sample solutions corresponding to spots on TLC

In order to obtain substances corresponding to each spot on the TLC plate, chromatography was performed on a solid-phase extraction column packed with silica gel (Bond Elut ${ }^{\circledR}$ SI, $500 \mathrm{mg}$ ). Hydrolyzate of Yucca extract prepared by a previously reported method ${ }^{3)}$ was dissolved in a small amount of hexane-ethyl acetate $(2: 1)$ mixture, and applied to the column. Fractionation was performed with $20 \mathrm{~mL}$ of the hexane-ethyl acetate $(2: 1)$ mixture. Fractions collected every $1 \mathrm{~mL}$ were subjected to TLC together with total sample solution ( $\mathrm{t}$ ) (hydrolyzate of Yucca extract prepared in a separate experiment), and analyzed by the TLC method described above. Fractions corresponding to the three major spots were combined (fractions $\mathrm{a}^{-} \mathrm{c}$ ). Fractions $\mathrm{a}^{-}$ c were divided into two parts, and evaporated to dryness under a stream of nitrogen.

\section{(2) Sample preparation for $G C / M S$ analysis}

One part of fractions $\mathrm{a}^{-} \mathrm{c}$ was dissolved in $1 \mathrm{~mL}$ of ethyl acetate (sample solutions $\mathrm{a}-\mathrm{c}$ ). The other was acetylated with $200 \mu \mathrm{L}$ of pyridine and acetic anhydride at $40^{\circ} \mathrm{C}$ for 30 minutes. After evaporation of the reagents under a stream of nitrogen, the residue was dissolved in $1 \mathrm{~mL}$ of ethyl acetate (sample solutions a'$\left.c^{\prime}\right)$. Half of the total sample solution (t) was acetylated as well.

(3) $G C / M S$ conditions

A $30 \mathrm{~m} \times 0.32 \mathrm{~mm}$ i.d. column (BPX 5, film thickness $0.25 \mu \mathrm{m}$, SGE International Pty., Ltd.) was employed for GC/MS. The column oven temperature program was as follows: $40^{\circ} \mathrm{C}(2 \mathrm{~min}) \rightarrow\left(10^{\circ} \mathrm{C} / \mathrm{min}\right) \rightarrow 320^{\circ} \mathrm{C}(30 \mathrm{~min})$. The column inlet pressure was $30 \mathrm{kPa}$ (helium), the interface temperature was $300^{\circ} \mathrm{C}$, the ion source temperature was $210^{\circ} \mathrm{C}$, and the scanned mass range was from 40 to 600 amu. Aliquots $(1 \mu \mathrm{L})$ of the sample solutions before (a$\mathrm{c}$ and $\mathrm{t})$ and after $\left(\mathrm{a}^{\prime}-\mathrm{c}^{\prime}\right.$ and $\left.\mathrm{t}^{\prime}\right)$ acetylation were applied to the GC column by on-column injection.

\section{GC analysis}

\section{(1) Sample preparation for GC analysis}

Samples were prepared as described previously ${ }^{3)}$. A portion of the sample solution was taken in a flask, and the ethyl acetate in the solution was removed under reduced pressure. The residue was acetylated in the same manner as the sample solutions used for GC/MS analysis.

\section{(2) Preparation of standard solution for $G C$}

Stock standard solutions of sarsasapogenin and smilagenin were prepared by dissolving $5 \mathrm{mg}$ of the standard substances in $50 \mathrm{~mL}$ of ethyl acetate. The stock solutions were diluted and mixed to prepare mixed standard solutions at a concentration of $1-400 \mu \mathrm{g} / \mathrm{mL}$. The standard solutions were acetylated in the same manner as sample solutions.

\section{(3) GC conditions}

The separation column and the column oven temperature program were the same as for the GC/MS analysis. The column flow was $2.6 \mathrm{~mL} / \mathrm{min}$ (helium). The detection temperature was $350^{\circ} \mathrm{C}$. Aliquots $(1 \mu \mathrm{L})$ of the acetylated sample solutions were injected into the GC column by on-column injection.

(4) Determination of sapogenins by $G C$

The amounts of sarsasapogenin and smilagenin were calculated by using calibration curves obtained with the corresponding standard substances.

\section{Results and Discussion}

\section{Detection of sapogenin by TLC}

Saponins in Yucca extract appeared blue on the TLC plate following the treatment with anisaldehyde reagent, probably due to the sugar moiety of the glycoside. However, sarsasapogenin exhibited a yellowishgreen color, characteristic of steroidal sapogenins. Hence, TLC of sapogenin was preferred over TLC of saponin for better selectivity to detect effective compounds in Yucca extract. Separation of sapogenins with various hexane-ethyl acetate mixtures ${ }^{4)}$ as a developing solvent was attempted, and the $2: 1$ mixture was chosen because of the relatively better separation of the three yellowish-green spots. HP-20 treatment was preferable to remove other color-developing substances on the TLC plate, i.e., sterols, and two blue spots (spots e and d in Fig. 1), which were later found to be hydroxylmethylfurfral and its ethyl adduct, respectively, that may have been formed from sugars during hydrolysis of the Yucca extract (data not shown). The detection limit by TLC for standard sarsasapogenin was $50 \mathrm{ng}$ $(1 \mu \mathrm{L}$ of $50 \mu \mathrm{g} / \mathrm{mL})$, corresponding to $0.025 \%$ in Yucca extract. 


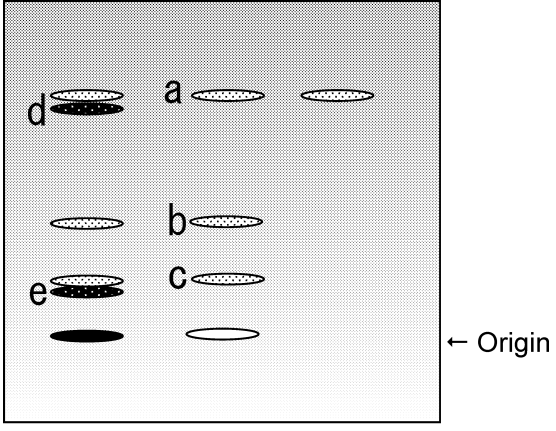

(i) (ii)

(iii)

Fig. 1. TLC of hydrolyzed Yucca extract

(i ) : hydrolyzate of Yucca extract without HP-20 purification

(ii): hydrolyzate of Yucca extract purified with HP-20 (iii): standard sarsasapogenin $\longrightarrow$ : yellowish green, blue

2. Investigation of spectrophotometrically determined substances

Three yellowish-green spots (spots a, b, c in Fig. 1) were observed on the TLC plate of the hydrolyzate of Yucca extract. They were assumed to represent the substances which exhibited a yellowish-green color with a maximum wavelength at around $430 \mathrm{~nm}$ in spectrophotometry. Figure 2 shows total and selected ion mass chromatograms for sample solution $t^{\prime}$ and $\mathrm{a}^{\prime}-\mathrm{c}^{\prime}$ (acetylated fractions corresponding to total hydrolyzate, and spots $\left.\mathrm{a}^{-} \mathrm{c}\right)$, obtained as described in the Experimental section. Peaks 1 and 2 corresponded to spot a, 5 and 6 to spot b, and 3 and 4 to spot c. The fragment ion observed at $m / z=139$ was the base peak in the mass spectra of 6 major and several minor GC peaks for these solutions. Because it is a typical fragment ion of steroidal sapogenin ${ }^{5}$, these peaks were assumed to represent steroidal sapogenins.

Peak 2 was the largest, and was identified as sarsasapogenin. Peak 1 followed, and was identified as smilagenin by comparing the retention times and mass spectra with those of standard substances. Mass spectra of

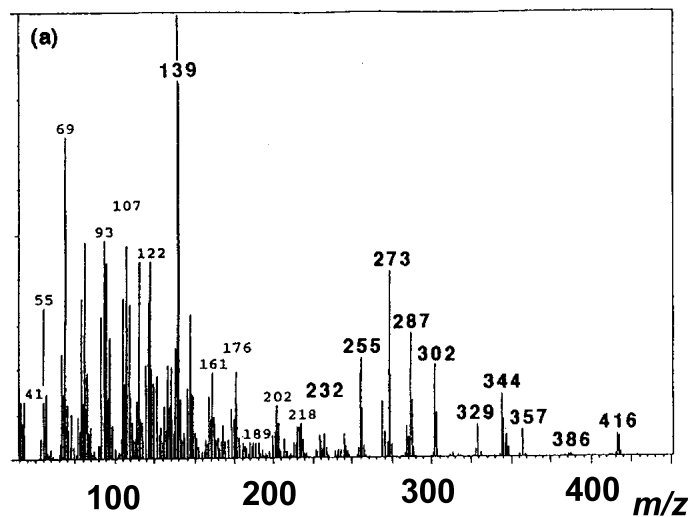

(t)

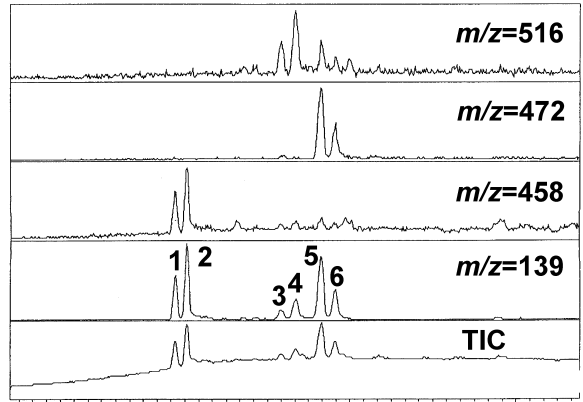

(a)

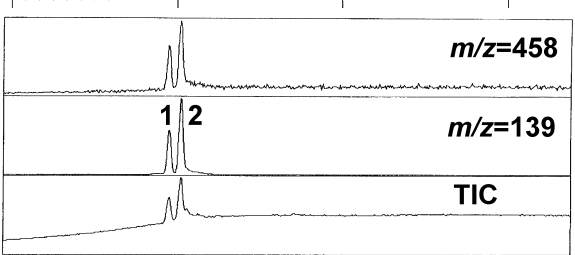

(b)

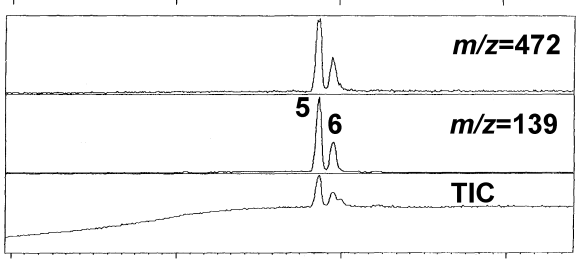

(c)

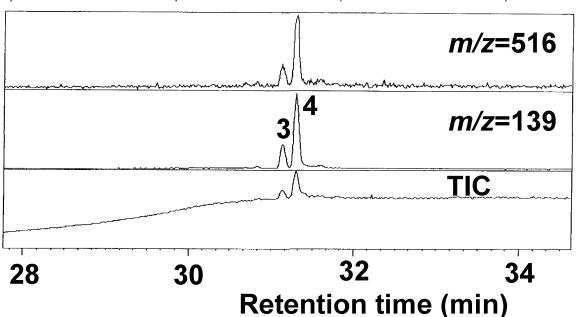

Fig. 2. Total ion and selected ion chromatograms of acetylated sapogenins in Yucca extract

(t): correspondsto totalhydolyzate

(a)-(c): selected ion chromatograms correspond to spots $\mathrm{a}-\mathrm{c}$

Peaks 1 and 2 : correspond to spot a in Fig. 1. Peaks 3 and 4 : correspond to spot c in Fig. 1.

Peaks 5 and 6 : correspond to spot $\mathrm{b}$ in Fig. 1.

peak 2 (before and after acetylation) are shown in Fig. 3.

The mass spectra of peaks 5 and 6 , and the corresponding peaks before acetylation were similar to those

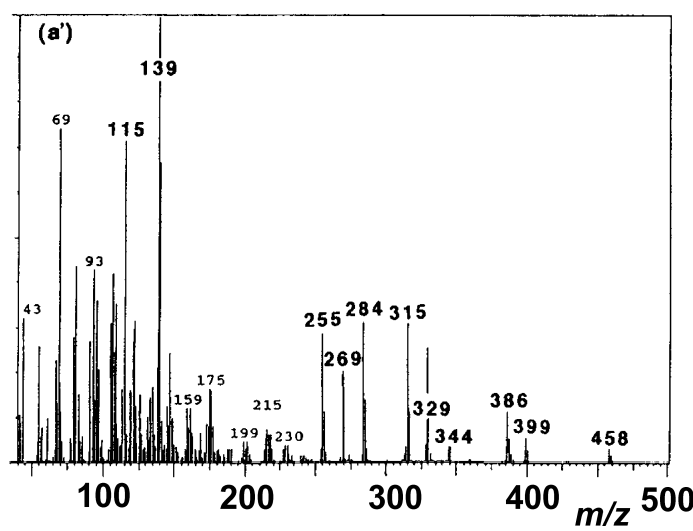

Fig. 3. Mass spectra of sarsasapogenins in Yucca extract before and after acetylation (a): before acetylation $\left(a^{\prime}\right)$ : after acetylation 
of hecogenin $[\{(25 R)$-12-oxo- $5 \alpha$-spirostan- $3 \beta$-ol $\}$; molecular ion at $m / z=430$ before acetylation, and $m / z=472$ after acetylation), but the retention times were different. Hence, these peaks were assumed to represent substances with structures similar to that of hecogenin. The presence of carbonyl groups in fraction b was confirmed by Fourier transform infrared (FT-IR) spectroscopy (data not shown).

Peaks 3 and 4 have ion peaks at $m / z=516$. Peaks corresponding to these peaks before acetylation have ion peaks at $m / z=432$. Steroidal sapogenins with two hydroxyl groups such as markogenin (25S)-5 $\beta$-spirostan- $2 \beta, 3 \beta$-diol $\}$ and samogenin $\{(25 R)-5 \beta$-spirostan- $\beta$, $3 \beta$-diol $\}$, gitogenin $\{(25 R)-5 \alpha$-spirostan- $2 \alpha, 3 \beta$-diol $\}$ and neogitogenin $\{(25 S)-5 \alpha$-spirostan- $2 \alpha, 3 \beta$-diol $\}$ that were found in the acid-hydrolyzed glycoside fraction of Yucca schidigera ${ }^{6}$ would give these ion peaks. Steroidal saponins which have these aglycones were isolated and identified from Yucca, as well ${ }^{7}$. Hence, peaks 3 and 4 might represent these sapogenins.

Although further investigation will be required to identify these compounds, these peaks were assumed to represent steroidal sapogenins from the base peak at $m / z=139$, the similarities of the mass spectra to those of known steroidal sapogenins, and the specific color developed on TLC.

\section{Determination of major sapogenins by $G C$}

A GC method was established for the determination of two major sapogenins, sarsasapogenin and smilagenin, which are the aglycones of major antimicrobial saponins $^{8)}$.

Although a GC peak of underivatized standard sarsasapogenin was observed, calibration curves were not linear, probably because polar hydroxyl groups in the compound would result in strong adsorption on the inner wall of the glass insert liner, or the surface of the separation column. Hence, derivatization with various reagents was investigated. Acetylation was chosen because the peak of the trifluoroacetate was broad, whereas that of the acetate was sharp.

Injection techniques (splitless injection and oncolumn injection) and GC columns (0.25, 0.32 and 0.53 mm diameter of BPX5) were next investigated. GC peak areas obtained by on-column injection into a 0.32 and $0.53 \mathrm{~mm}$ column were 5 times larges than those obtained by splitless injection into a 0.25 or 0.32 diameter capillary column. However, the separation between neighboring sapogenin peaks with the $0.53 \mathrm{~mm}$ column was insufficient. GC peaks with on-column injection into the $0.32 \mathrm{~mm}$ column were twice as large as those into the $0.25 \mathrm{~mm}$ column. Thus, we chose on-column injection and a 0.32 diameter column.

The calibration curves were linear at $1-400 \mu \mathrm{g} / \mathrm{mL}$ $\left(R^{2}=0.9991\right)$, when $1 \mu \mathrm{L}$ was injected. Hence the detection limit (referring to the sample) was $10 \mu \mathrm{g} / \mathrm{g}$. Recoveries from Yucca extract were 95.1-99.8\% $(n=3)$.

A typical gas chromatogram of Yucca extract is shown in Fig. 4.

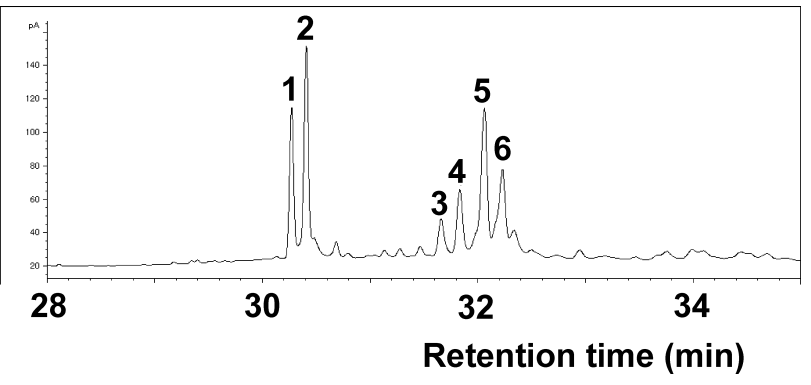

Fig. 4. Gas chromatogram of acetylated sapogenins in Yucca extract

Peaks: 1, smilagenin; 2, sarsasapogenin

Table 1. Concentrations of Sapogenins in Yucca Extract Used as Food Additive

\begin{tabular}{cccc}
\hline \hline Sample & Sarsasapogenin & Smilagenin & $\begin{array}{c}\text { Total } \\
\text { sapogenins }\end{array}$ \\
\hline 1 & 0.66 & 0.26 & 1.89 \\
2 & 0.58 & 0.25 & 1.82 \\
3 & 0.63 & 0.19 & 1.94 \\
4 & 0.66 & 0.22 & 2.03 \\
\hline
\end{tabular}

a) Calculated from the sum of the GC areas of peaks 1-6 in Fig. 4

\section{Contents of major sapogenins}

Contents of sarsasapogenin and smilageninin in commercial Yucca extracts $(n=4)$ were $0.58-0.66 \%$ and $0.19-0.26 \%$, respectively (Table 1 ). The sum of the two compounds was approximately 0.9\%. Total steroidal sapogenin amounts in Yucca extract were 1.8-2.0\%, as estimated by summing the areas of the six GC peaks for which $m / z=139$ was observed in mass spectra, using a calibration curve for standard sarsasapogenin, on the assumption that the FID response of these compounds was the same as that of sarsasapogenin. The total amounts of steroidal sapogenin estimated by GC in this way (Table 1) were similar to those obtained by spectrophotometry ${ }^{3}$. The sum of sarsasapogenin (peak 2 in Fig. 2) and its stereoisomer smilagenin (peak 1 in Fig. 2) accounted for nearly half of the steroidal sapogenins, and these two sapogenins were considered to be major sapogenins in Yucca extract.

\section{Conclusion}

The major spectrophotometrically determined substances in Yucca extract were found to be steroidal sapogenins. Sarsasapogenin and smilagenin were the dominant sapogenins, the sum of which in Yucca extract was $0.9 \%$. The total amount of sapogenins estimated by GC was approximately $2 \%$, which is similar to that measured by spectrophotometry.

\section{Acknowledgments}

We thank Professor Ichiro Kudo and Professor Yoshiteru Ida from Showa University for helpful advice during this work, and Maruzen Pharmaceuticals Co., Ltd. for donating Yucca extract. 


\section{References}

1) List of Existing Food Additives (List of food additives from natural origin compiled and published by the Ministry of Health and Welfare on April 16, 1996): The Ministry of Health and Welfare Announcement, No. 120, Tokyo, Japan.

2) Tanaka, O., Tamura, Y., Masuda, H., Mizutani, K., Application of saponins in foods and cosmetics: saponins of Mohave Yucca and Sapindus mukurossi. Adv. Exp. Med. Biol., 1-11 (1996).

3) Uematsu, Y., Hirata, K., Saito, K., Kudo, I., Spectrophotometric determination of saponin in Yucca extract for food additive use. J. AOAC Int., 83, 1,451-1,454 (2000).

4) Blunden, G., Hardman, R., Quantitative estimation of monohydroxy saturated steroidal sapogenins in plant materials by densitometric thin-layer chromatography. J. Chromatogr., 34, 507-514 (1968).
5) Budzikiewicz, H., Djerassi, C,. Williams, D. H., Structure elucidation of natural products by mass spectrometry, Volume II: Steroids, terpenoids, sugars, and miscellaneous classes. Holden-Day, Inc., 1964, p. 112-113.

6) Kaneda, N., Nakanishi, H., Staba, E. J., Steroidal constituents of Yucca shidigera plants and tissue cultures. Phytochemistry, 26, 1,425-1,429 (1987).

7) Miyakoshi, M,. Tamura, Y., Masuda, H., Mizutani, K., Tanaka, O., Ikeda, T, Ohtani, K., Kasai, R., Yamasaki, K. Antiyeast steroidal saponins from Yucca schidigera (Mohave Yucca), a new anti-food-deteriorating agent. J. Nat. Prod., 63, 332-338 (2000).

8) Killeen, G. F., Madigan, C. A., Connolly, C. R., Walsh, G. A., Clark, C., Hynes, M. J., Timmins, B.F., James, P., Headon, D. R., Power, R.F, Antimicrobial saponins of Yucca schidigera and the implications of their in vitro properties for their in vivo impact. J. Agric. Food Chem. 46, 3,178-3,186 (1998). 